\title{
Research on integrated manufacturing technology of CNC machine tool and 3D printing
}

\author{
Shengyu $\mathrm{Lu}^{1}$ \\ ${ }^{1}$ Shandong technician college of water conservancy,Shandong,Zibo,China,255130.
}

\begin{abstract}
CNC machine tools and 3D printing technology belong to two different processing methods, which have their own advantages and disadvantages. In order to promote the development of high-end manufacturing industry, we can combine $\mathrm{CNC}$ machine tools and 3D printing technology to give full play to their advantages. This paper analyzes the integrated manufacturing technology of CNC machine tools and 3D printing, further improve the level of industrial production in China.
\end{abstract}

\section{Introduction}

The development level of China's manufacturing industry continues to improve. In China's industrial production process, CNC machine tools play an important role. However, there are some problems in the use of CNC machine tools in actual production, such as a large number of Debris Waste in the production process, which seriously pollutes the environment. In recent years, with the continuous development of 3D printing technology, many factories in China began to use 3D printing technology to add metal powder layer by layer in the production process to ensure the production effect. In the process of producing automobiles and airplanes, 3D printing technology is also used to promote the sustainable development of China's manufacturing industry. But in the production process, only using $3 \mathrm{D}$ printing technology, the overall strength is relatively low. Combined with CNC machine tools and 3D printing technology, 3D printers can be filled with scraps produced by $\mathrm{CNC}$ machine tools. After reasonable processing, the manufacturing intensity of parts can be improved significantly, and the production efficiency can be significantly improved. At the same time, the scraps can be reused to save production costs and avoid production pollution.

\section{Analysis of CNC machine tools and 3D printing technology}

\subsection{Concept of CNC machine tools and 3D printing}

CNC machine tool is a kind of mechanical and electrical production equipment, which can improve the automation level of parts processing in China. According to the processing requirements, $\mathrm{CNC}$ machine tools program processing process, and then input the program to the control center to effectively control the actual operation of mechanical equipment. Using $\mathrm{CNC}$ machine tools, raw materials can be cut and processed to obtain products. In the process of machining, the use of CNC machine tools and sensors to monitor the whole processing process can timely adjust the operation process of mechanical equipment and ensure the reliability and accuracy of parts processing. CNC system has the advantage of flexibility and can guarantee the overall machining accuracy. Therefore, CNC machine tools are widely used in aerospace processing. 【1】

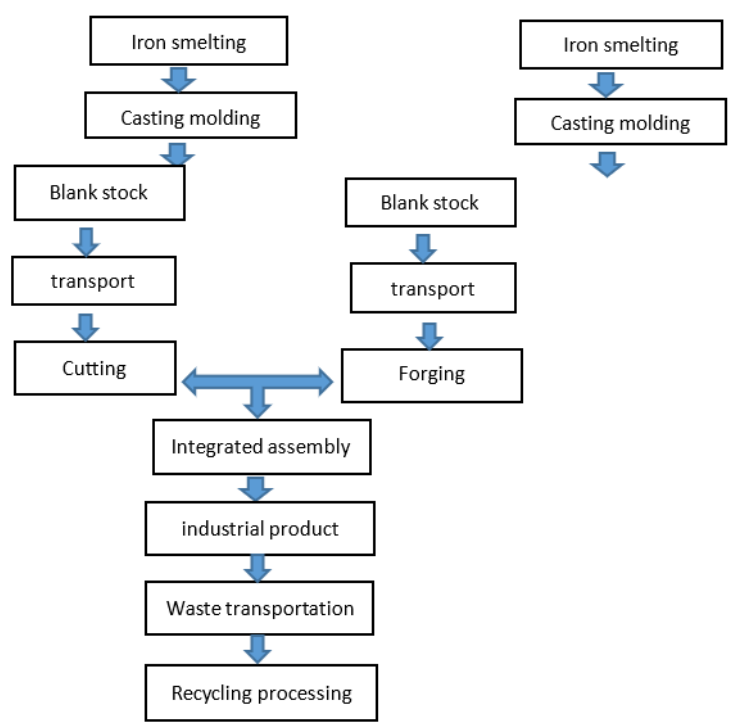

Production cycle of $\mathrm{CNC}$ machine tools

$3 \mathrm{D}$ printing technology innovates the processing and manufacturing mode. By using additive manufacturing technology, parts with complex structure can be produced and processed. The technicians sliced and layered 3D solid model by computer software, transformed the 3D shape information of parts into 2D graphics information, and filled each group of 2D graphics according to the processing requirements. In the process of production and processing, the path information is imported into the 
printer control system. The printer can use the filling path to melt and accumulate the filling materials. After one layer reaches the thickness requirement, the next layer is filled, and finally the three-dimensional solid product is established. 3D printing technology is mainly to overlay printing materials layer by layer, which can process difficult parts. With the continuous development of 3D printing technology, various types of materials can be used. Therefore, the application fields of 3D printing technology are expanded, which can promote the sustainable development of China's industrial production industry.

\subsection{Features of CNC machine tools and 3D printing}

China's industrial production industry continues to develop, in each stage of continuous innovation of production technology. In the manufacturing process of equal materials, the weight of materials will not change before and after processing. This kind of technology includes casting, forging and welding. Reduction manufacturing technology processes materials through cutting, and finally processes them into designed shapes, and uses various equipment to cut and process various materials. Using additive manufacturing technology, mainly using UV curing and laser sintering technology, processing raw materials for design shape. The development level of China's industrial processing technology is constantly improving, which not only changes the traditional production and processing concept and mode, but also reduces the overall processing cost, reduces the energy consumption, and improves the production efficiency. 【2】

CNC machine tool processing is mainly using the way of reducing materials. In the processing work, we need to use tools and fixtures to cut raw materials, remove the redundant parts, and finally make them as the design shape. $\mathrm{CNC}$ machine tools have high automation and intelligence, can adapt to various processing objects, can realize batch production, and can realize small batch processing. In the process of processing various parts, the technicians do not need to adjust the machine tool, at the same time, they can optimize the processing program, input the corresponding program in the control panel process, operate the corresponding process, save the overall production cycle and reduce the equipment replacement time. Numerical control machine tool uses digital signal to control the production process. In the process of processing, the component error can be compensated, so that the machining accuracy can be improved, and the processing quality can be guaranteed. The use of CNC machine tool automation production mode, can improve the overall production efficiency, through the improvement of related processes, can continue to process multiple processes, to avoid too much time because of the conversion program. Because the NC machine tool in the processing process is mainly to use the designed program, after starting the input program, can automatically continuous processing, reduce the work intensity of the staff. But this also puts forward higher requirements for the staff, operators need to be proficient in operating procedures to achieve the efficiency of machine tool processing.

3D printing technology is a kind of additive manufacturing technology, which can improve the overall working speed, reduce the overall cost, and the related operation is relatively simple. Therefore, 3D printing technology is widely used in modern production. Compared with the material reduction manufacturing technology, 3D printing technology can process and produce various types of products without using tools and fixtures, and can freely switch various processing programs. In the process of parts production, technicians only need to call different files, design parts through computer software, and put them into production after completing the design. It can promote the speed of new product research and development, reduce the material reduction manufacturing process, and improve the digital and intelligent level of product manufacturing. The technical personnel can use the computer to operate the working procedures, with high production efficiency. In the production process, because the melting and setting speed is relatively fast, it can improve the compactness and uniformity of the structure of the parts, reduce the incidence of structural defects, and ensure the plasticity and corrosion resistance of the material. Because of the special processing method, it can combine any mode and structure, which is conducive to the processing of parts with complex structure. 【3】

\subsection{Limitations of CNC machine tools and 3D printing technology}

In the process of using $\mathrm{CNC}$ machine tools, the material utilization rate is relatively low, and the overall processing time is relatively long. Increasing the material utilization rate can save a lot of steel consumption. For example, in the aeroengine manufacturing work, in the process of processing parts, the overall utilization rate of materials is only $15 \%$.

Nowadays, 3D printing technology is not perfect, and the production and processing work has limitations. For example, 3D printing technology can not be used in processing high-strength parts. Technicians need to accurately control high-performance parts, but this kind of parts can not use 3D printing technology.

\section{The necessity of combination of CNC machine tool and 3D printing technology}

Traditional treatment methods will consume more materials and energy, and also cause environmental pollution problems, so our technical personnel need to deal with this problem reasonably. The use of $3 \mathrm{D}$ printing technology can reduce the problem of material waste, at the same time, it can simplify the steps of template making, improve the product manufacturing efficiency, thus improving the overall production efficiency. In addition, $3 \mathrm{D}$ printing technology is used to reduce energy consumption and reduce the time cost and labor cost of industrial production. However, 3D printing technology is 
not perfect, which limits the development of processing products. For example, it is not suitable to use 3D printing technology in the production of high-density metal parts, such as the high-performance parts of aircraft engines. Therefore, it is necessary to combine CNC machine tools and $3 \mathrm{D}$ printing technology to improve the overall production efficiency, reduce the waste of resources and avoid environmental pollution in the production process. 【5】

The combination of $\mathrm{CNC}$ machine tool and 3D printing technology can form a composite machine tool. One machine tool can use the two technologies. In the composite machine tool, the materials processed by numerical control can be used as raw materials for 3D printing. After $3 \mathrm{D}$ printing, parts can be processed by numerical control technology to improve the surface smoothness and break through the limitations of the two technologies. Using the integrated manufacturing technology of $\mathrm{CNC}$ machine tool and 3D printing, the traditional processing method can be innovated and great work value can be created. After the combination of the two technologies, the problem of material waste can be avoided by using the composite machine tool. At the same time, the material can be recycled in production, so that the utilization rate of data is improved. The operation technology of the composite machine tool is relatively simple. The operator can complete the processing work with one workstation, so the overall process is simplified. In the compound machine tool, two technologies can be operated to reduce the overall technical investment. The parts produced have high cost performance, which can reduce the overall cost and enhance the performance of the parts.

\section{Application of integrated manufacturing technology of CNC machine tool and 3D printing technology}

In view of the traditional processing and production technology, mainly for raw materials to implement cutting, forging and bending, assembling a variety of components for products, and finally need to collect and transport fertilizer uniformly to achieve recycling processing. Using the integrated manufacturing technology of CNC machine tool and 3D printing can give full play to the advantages of the two. Technicians need to select the specific processing form reasonably according to the processing requirements, and process the products efficiently. If the product strength requirements are relatively high, $\mathrm{CNC}$ machine tools can be used to complete the processing work; if the strength is relatively low, 3D printing technology can be used to produce products and integrate production resources organically. The integrated manufacturing technology of CNC machine tool and 3D printing has significant production advantages, which can simplify the production process, allocate and utilize raw material resources efficiently, and reduce material loss and labor loss. 【6】

In the integrated manufacturing process of $\mathrm{CNC}$ machine tools and 3D printing, material reduction and additive processing are combined to recycle the materials in the process of material reduction, and the products with low strength can be processed by adding materials. In the actual work process, it is necessary to use CNC machine tools to process high strength parts. After using metal crusher, scrap will be produced, which can be further recycled after being processed into powder. Metal powder is imported into $3 \mathrm{D}$ printer, which can be processed into parts. Finally, through assembly and manufacturing, highquality industrial products are formed. Using this process, the processing requirements of different products can be met, and the powder produced by processing can be recycled and the comprehensive benefit of production can be improved.

Using the integrated manufacturing technology of CNC machine tools and 3D printing technology, high-end products can be produced. The integration of the two technologies to develop composite machine tools can improve the competitiveness of manufacturing enterprises and efficiently manufacture and maintain load parts. At present, many countries have developed high-end composite machine tools, and can ensure the actual application effect. For example, complex machine tools can be used to process difficult products, such as parts in the aerospace field, which can improve the processing level of parts and meet the requirements of product manufacturing. Two kinds of cladding heads can be used in the composite machine tool, which can be switched flexibly after the cladding heads are installed in the spindle. In practical work, the technical personnel need to select the cladding head reasonably according to the characteristics of the parts and processing conditions. Compound machine tool can use five axis turn milling to realize compound processing effect, and can easily produce multi prism forgings and castings. The use of coincidence machine tools can reduce the waste of production materials, efficiently process complex parts, and improve the smoothness of 3D printing surface. In the industrial field with high processing requirements, it is suitable to use $\mathrm{CNC}$ machine tools and $3 \mathrm{D}$ printing integrated manufacturing technology. (7)

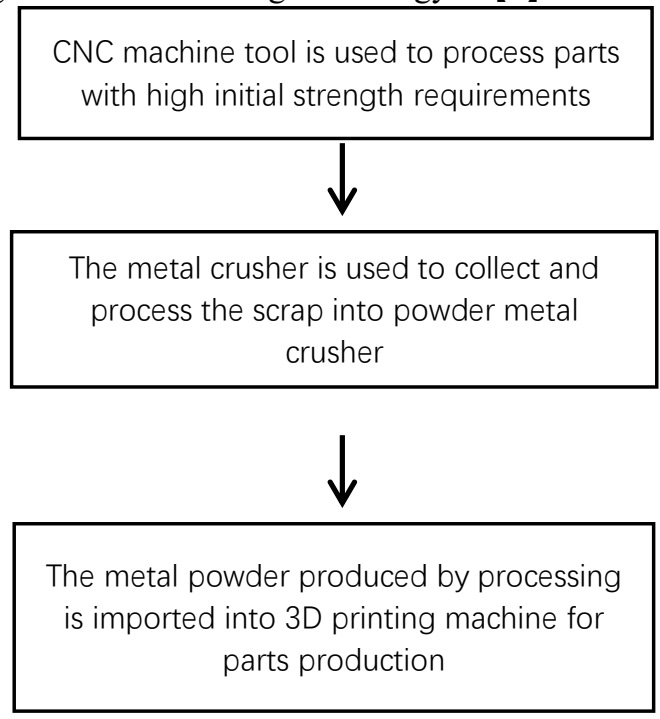




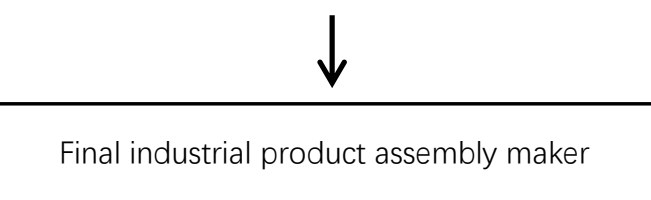

Integrated manufacturing process of CNC machine tool and 3D printing

The integration of CNC machine tool and 3D printing technology has many advantages, but there are also shortcomings. In the process of CNC machining, cutting fluid is needed. After machining, a part of cutting fluid will remain. After mixing 3D printing particles, the laser beam absorption rate will be affected, and the dilution effect of filling materials inside the substrate will be affected. In the $3 \mathrm{D}$ printing process, the material powder will also wear the machine tool guide system, so technicians need to take targeted preventive measures. In the heat treatment work, under the influence of heating and cooling thermal cycle, the residual stress will be produced in the added material, which will release the residual stress in the subsequent processing, which will affect the accuracy of the part geometry. In the integrated manufacturing process of CNC machine tools and 3D printing, technicians need to improve the production process according to the actual production situation, reduce the adverse impact between the two technologies, and improve the production efficiency and quality. 【8】

\section{Conclusion}

The use of CNC machine tools and 3D printing integrated manufacturing technology, mainly combined with the application of additive manufacturing and material reduction manufacturing, can give full play to the advantages of the two technologies, and at the same time can overcome the shortcomings of the two technologies, make efficient use of production resources, optimize the overall production mode, and further improve the production efficiency. At present, China's resources are relatively tight, but also facing the problem of environmental pollution, the use of CNC machine tools and $3 \mathrm{D}$ printing integrated manufacturing technology can upgrade and transform the industrial production industry. However, the integrated manufacturing technology of $\mathrm{CNC}$ machine tools and 3D printing is not perfect in China. The relevant research and development personnel need to strengthen the research, constantly improve the integrated manufacturing technology, and further develop the processing and manufacturing industry in China.

\section{Reference}

1. Yang Wenlong. Innovative research on mechanical structure design and manufacturing technology of $\mathrm{CNC}$ machine tools [J]. Internal combustion engine and accessories, 2020 (11): 102-103

2. Wu Zhiwei, $\mathrm{Wu}$ Xuemeng. Discussion on the new development of mechanical structure design and manufacturing technology of CNC machine tools [J]. China Metal Bulletin, 2020 (02): 46-47
3. Gao aisong. Discussion on new trends of mechanical structure design and manufacturing technology of CNC machine tools [J]. Hubei agricultural mechanization, 2019 (10): 17

4. Liu Zhongyong. Discussion on the new development of mechanical structure design and manufacturing technology of CNC machine tools [J]. Southern agricultural machinery, 2019,50 (06): 116

5. An Ruwei, Wang tingmeng, Zhang Taiyong, Liu Xiao, Tan Lijuan. Discussion on the new development of mechanical structure design and manufacturing technology of $\mathrm{CNC}$ machine tools [J]. Internal combustion engine and accessories, 2019 (03): 77-78

6. Yao Jie. Research and Discussion on mechanical structure design and manufacturing technology of CNC machine tools $[\mathrm{J}]$. China Equipment Engineering, 2017 (15): 202-203

7. Yang Xianqi, min Xu, Jin Hao, GE Xiaole, Liu Tengfei. Die process design and NC network manufacturing technology of typical stamping parts [J]. Journal of Huangshan University, 2017,19 (03): 40-42

8. Ge Jianwei. New development of mechanical structure design and manufacturing technology of CNC machine tools [J]. Industrial design, 2016 (07): $152+154$ 